\title{
The Relation between Personality Characteristics and Self-Efficacy and Successful and Unsuccessful Aging
}

\author{
Mina Kafaei kivi ${ }^{1}$, Dr Abdollah Motamedy ${ }^{2}$
}

\section{ABSTRACT}

The aim of the present study is to investigate the relation between personality characteristics and general self-efficacy with successful and unsuccessful aging. In this research, 194 old people, who were members of Tehran's Retired Staff Club of Education Ministry, were selected as the available sample. This population answered to Diner's life satisfaction and Goldberg's general health questionnaires; 30 people who had acquired the highest grades were selected as successful and the other 30 people who had acquired the lowest grades were selected as unsuccessful aged people. Personality characteristics and self-efficacy of these two groups were measured using Neo questionnaire and Shrer's self-efficacy questionnaire. The obtained results were analyzed using $\mathrm{T}$ statistical tests, Pearson correlation, and multiple regression; the results showed a significant relation between personality characteristics and the feeling of self-efficacy between successful and unsuccessful aged people. The results of multiple regression analysis demonstrated that the two characteristics of neuroticism and conscientiousness could better predict the feeling of self-efficacy among aged people.

Keywords: Successful Aging - Life Satisfaction - General Health - Personality Characteristics Self-Efficacy

Developments in medical sciences and improvement of life conditions have resulted in an increase in the number of 60-year old people. It is expected that this population will increase up to $23 \%$ in the middle of the $21^{\text {st }}$ century (Gliken, 2009). As Foos and Clark (2009) believe, many factors are related with the increase of aged people population of which the decrease in birth rate, changes in hope for life, and the shocking growth of children born in the same period can be mentioned.

\footnotetext{
${ }^{1}$ M.A in psychology, Allame Tabatabaee university, Tehran, Iran

${ }^{2}$ Assistant professor , Allame Tabatabaee university, Tehran, Iran

*Responding Author

(C) 2016 I M Kivi, A Motamedy; licensee IJIP. This is an Open Access Research distributed under the terms of the Creative Commons Attribution License (http://creativecommons.org/licenses/by/2.0), which permits unrestricted use, distribution, and reproduction in any Medium, provided the original work is properly cited.
} 


\section{The Relation between Personality Characteristics and Self-Efficacy and Successful and Unsuccessful Aging}

In gerontology, age is considered as a criterion for successful aging. For years, living a long life had been a dream. On the other hand, it had been accompanied by some problems; negative experiences would increase with aging, aged people would lose their old friends, and they would suffer from different diseases. In 1995, Gerontological Society of America selected the motto of "adding life to age" and not adding age to life (Orrell, and Specto, 2009).

Hoyer and Roodin (2009) consider successful aging as the result of the three following performances and their effects: being away from disease and disability, continuing effective physical activities, and continuing social activities in the society (Bengeston, Kuypers, 1985; Palmore, 1979; Rowe and Kahn, 1987; and Ryff, 1982, cited in Orrell, and Specto, 2009). Successful aging is not merely measured based on life satisfaction as was common in traditional viewpoints of quality of life researches; rather, it includes a combined approach of different qualitative and quantitative aspects of aging. They propose several criteria for successful aging:

- The length of lifetime, life satisfaction, biological health, social capability

- Psychological health, personal control, and perceptual efficiency.

Buttler et al., 1991 (cited in Gliken, 2009) regard positive confrontation strategies as the key to experience successful aging; they enable aged people to change their priorities. Fundamentally, a certain collection of ideologies and attempts is required to help aged people remain independent, productive, and socially active as much as possible, contrary to the present contrasts and threats.

The results of studies in different cultures have showed that internal and personality factors are significantly related with the mental image of a good life (Foos and Clark, 2009). A person's psychiatric personality and structure is mainly related with their mental health. Personal factors indirectly affect people's life quality through influencing their mental health (Bond and Corner, translated by Mohaqeqi Kamali, 1389). A scientific definition of personality defines it as including sustainable patterns of feeling, thinking, and behavior. A broad definition of personality provides the possibility of studying different aspects of a person (Pervin, Cervone, and John, 2005). New personality theories emphasize on the fact that there is a great potential in changing personality characteristics among adults, unlike the apparent stability of their characteristics. Hooker and Macadams (2005, cited in Hoyer and Roodin, 2009) state that combining information on personal self-regulation and self-expression strategies and characteristics can be useful in obtaining a comprehensive image of adults' personality. Characteristics' approach towards personality is not necessarily inconsistent with other approaches. For instance, an adult person may be stable regarding their personality characteristics; they may use other useful strategies to administer and manage stressful events and other situations and employ different solutions to interpret their life environmental situations. In addition to personal characteristics which influence cognitive performances and

(c) The International Journal of Indian Psychology, ISSN 2348-5396 (e)| ISSN: 2349-3429 (p) | 103 


\section{The Relation between Personality Characteristics and Self-Efficacy and Successful and Unsuccessful Aging}

neural damages (Huffer and Elvin, 2008), all human beings are equipped with a belief system which structures their world, gives meaning to their experiences, and without which, they will be confused. Some beliefs are signs of a dynamic self and a dynamic world; they own a great potential to create change. These beliefs encourage us to search for correcting and optimizing defects and shortcomings and solve our problems (Bandura, Locke, 2003). In some literature reviews regarding aged people studies, it has been realized that self-efficacy beliefs can not only predict aged people's subjective well-being, but also they provide them with a framework for life satisfaction and confidence. Those aged people who have high self-efficacy can better tolerate stress such as fear, anxiety, and loneliness and can face traumas (Fry and Kiz, 2010).

Many studies have been conducted on variables of personality characteristics and self-efficacy and factors related with successful aging, some of which determine the relation between these factors.

Veljko (2011) performed a research on the role of personality characteristics in predicting subjective well-being and life satisfaction; in this research, the five-factor model of Zuckerman was employed; the results showed that considering individual differences, personal characteristics have different powers in describing well-being and life satisfaction. This study showed that neuroticism and anxiety directly influence the affective aspect and life satisfaction. In this regard, Schenhofen, Reynilds, Pederse, and Gatz (2010) investigated the relation between the factor of openness to experience and aging with cognitive performances. Factors detected in the cognitive field included verbal ability, spatial ability-memory functioning, and the total grades in these tests. This hypothesis demonstrated that openness to experience is related with better performances in cognitive tests; these people's cognitive performances showed less reduction by age increase. Openness to experience cannot predict cognitive performances in each age group; among personality characteristics, however, less attention has been paid to openness to experience in gerontology. Some researches predict that cognitive damages among aged people are indicators of personal aspects' effects which play roles in causing chronic diseases and neuron degeneration directly or indirectly. Regarding personality characteristics and cognitive damages among aged people, Jakson, Balota, and Head (2009) attempted to investigate the relation between personal characteristics and the relative reduction of gray and white matters in the brain in the forehead and temple parts. The results of this research in a 79-person group aged between 44- 88 showed that neuroticism is accompanied by low performance capacities in the brain and more reduction of gray and white matters in the brain due to age increase. There is a positive relation between conscientiousness and more capacities in brain performance and less reduction of gray and white matters in the forehead and temple parts.

Considering the mentioned results, personality characteristics affect both a person's self-image and the characteristics related with their compatibility with life; they include attitudes, personal

(C) The International Journal of Indian Psychology, ISSN 2348-5396 (e)| ISSN: 2349-3429 (p) | 104 


\section{The Relation between Personality Characteristics and Self-Efficacy and Successful and Unsuccessful Aging}

goals, and self-efficacy beliefs. Memory self-efficacy is one's beliefs on one's mastery of memory functioning. Assuming that aged people's health and their complaint from their memory is more related with a person's self-efficacy beliefs, rather than their real capacities which are objectively measured, Aben, Ponds, Visser, Busschbach, and Ribbers (2011) studied selfefficacy beliefs and memory related complaints in aged patients. In this cross sectional study, 136 patients were studied 18 months after the occurrence of the disease; their self-efficacy, depression, and methods to cure them were measured and evaluated. Patients were divided into 2 groups including patients with memory complaints and aged people who were satisfied with their memory functioning. The statistical results indicated that low grades of self-efficacy created an independent variable in memory complaints, depression, and age-related problems. In the studies conducted by Davy (2011) in Carolina, it was found out that the feeling of self-efficacy in weight control among the elderly (one's beliefs that a person can control their weight) is directly related with the weight loss process. The combination of self-efficacy beliefs with physical treatment activities ends in better results in weight loss and eventually, the aged people's physical health. Weight loss is one of the best solutions in decreasing the risk of cardiovascular diseases among the elderly. There are many factors affecting weight loss of which psychological influences, social resources, and genes' effects can be named.

Extended studies have demonstrated the relation between personality characteristics and two components of subjective well-being (subjective happiness and life satisfaction).

The results of researches performed by Strobel, Turnasja, and Sporrle, (2011) showed that there is a relation between neuroticism, extraversion, openness to experience, and having a conscience and subjective well-being; self-efficacy plays the role of a mediator. The results of this research shed light on the importance of cognitive beliefs in performances related with personal characteristics and subjective well-being. Physical diseases are the result of chronic stress; personal characteristics are related with diseases through different ways such as appraising and confronting with daily life difficulties. A research was conducted with a large sample aiming to investigate the probable relation between the perceived stress and personal aspects (extraversion and openness to experience) and the identification of the role of general self-efficacy. The sample concluded 3471 randomly selected participants with the mean age of 69. Personal characteristics were measured using NEO FFI test. The results showed that there was a negative relation between extraversion, conscientiousness, openness to experience, and being acceptable and the perceived stress if self-efficacy would act as a mediator. Self-efficacy played the strongest role in characteristics of conscientiousness and extraversion (Ebstrup, Eplov, Jorgensen, 2011). Self-efficacy as a mediator changes the interpretation and effect of the perceived stress; the results of this research proved that self-efficacy is of the important factors of the relation between personality and the perceived stress. Self-efficacy beliefs determine how people remove obstacles in acquiring and moving towards health; people with weak efficacy are

(c) The International Journal of Indian Psychology, ISSN 2348-5396 (e)| ISSN: 2349-3429 (p) | 105 


\section{The Relation between Personality Characteristics and Self-Efficacy and Successful and Unsuccessful Aging}

easily convinced that their personality and cognitive structure do not have the required flexibility to overcome health problems and they give up easily.

Considering the research results on self-efficacy, it was found out that when people believe in their ability to exert influence, their strategies for becoming successful become affected; people with high self efficacy can resist more against problems. Believing in self-efficacy affects people's efforts and their resistance against problems and anxiety. Those aged people with weak self-efficacy have less psychological and physical health; these aged people cannot easily deal with diseases and stress. Consequently, according to the results of the mentioned research, it has been attempted to investigate the relation between personality characteristics and general selfefficacy and successful and unsuccessful aging. To this end, the following hypotheses are considered.

Personality characteristics are different between successful and unsuccessful aged people. The feeling of self-efficacy is different between successful and unsuccessful aged people. There is a relation between personality characteristics among aged people.

\section{METHODOLOGY}

The present research is of correlation type. Its statistical sample includes all old women and men (above 60) who were members of Tehran's Retired Staff Club of Education Ministry over the period of 90-91. Regarding the size of the research population (n), the sample size was determined as 194 people based on Cochran formula; this number was selected by convenience sampling.

Successful aging was measured using two questionnaires of Goldberg's (1988) psychological health and Diner's (1993) life satisfaction. Those aged people acquiring the highest grades in both questionnaires were regarded as successful aged people.

In this research, psychological health and life satisfaction questionnaires were distributed among the aged people in the sample who agreed to participate; then, Shrer's self-efficacy and Neo personality characteristics (1985) questionnaires were completed by the participants.

In order to analyze data, statistical indices such as mean, standard deviation, $\mathrm{T}$ test, Pearson correlation, and multiple regression analysis were used.

\section{RESULTS}

Analyzing the descriptive information related with demographic characteristics indicated that women with $64 \%$ formed the main part of the sample. The age group of $66-70$ with $38 \%$ and the age group of $76-80$ with $16.5 \%$ had the most and the least percentage of the sample, respectively; 
$62.4 \%$ of the sample was married. Regarding education degree, most members had B.A/ B.Sc. with $38.7 \%$.

In order to compare variables in two groups of successful and unsuccessful aged people, life satisfaction and general health questionnaires were used; to do so, the sample group with 194 members were divided into two 97-member groups of high general health and weak general health based on the grades obtained from general health questionnaire; then, both groups were ordered based on the grades obtained from life satisfaction questionnaire; the first 30 people with the highest grades from life satisfaction questionnaire in the 97-member group were considered as having higher psychological health and were selected as successful aged people and the last 30 people having lower grades from life satisfaction questionnaire in the 97-member group were selected as unsuccessful aged people.

\section{An Interpretive Analysis of the Research Hypotheses}

The results of the first hypothesis have been presented in Table 1. Considering this information, the hypothesis stating the difference between characteristics of neuroticism, extraversion, conscientiousness, and being acceptable among successful and unsuccessful aged people is supported with 99\% certainty (sig < 0.01) and the null hypothesis is rejected. Only the characteristic of openness to experience was the same between successful and unsuccessful aged people; therefore, the null hypothesis is supported.

Table 1: The Result of $t$ Test in Comparing Personality Characteristics between Successful and Unsuccessful Aged People (df= 58)

\begin{tabular}{|c|c|c|c|}
\hline Variable & $\mathbf{t}$ & $\begin{array}{c}\text { Level of } \\
\text { Significance }\end{array}$ & Mean Difference \\
\hline neuroticism & 9.212 & 0.0001 & 16.73333 \\
\hline Extraversion & -6.317 & 0.0001 & -9.66667 \\
\hline $\begin{array}{c}\text { Openness to } \\
\text { Experience }\end{array}$ & 1.961 & 0.055 & 3.13333 \\
\hline Conscientiousness & -3.500 & 0.001 & -5.06667 \\
\hline Being Desirable & -6.520 & 0.0001 & -9.40000 \\
\hline
\end{tabular}

The results of $\mathrm{T}$ Test of the second hypothesis have been reported in Table 2. According to this table, the null hypothesis is rejected with 99\% certainty (Sig <0.01) and the feeling of selfefficacy is significantly different between successful and unsuccessful aged people. 
The Relation between Personality Characteristics and Self-Efficacy and Successful and Unsuccessful Aging

Table 2: The Result of $t$ Test in Comparing Self-Efficacy Feeling between Successful and Unsuccessful Aged People

\begin{tabular}{|c|c|c|c|c|}
\hline Variable & $\mathbf{t}$ & $\begin{array}{c}\text { Level of } \\
\text { Freedom }\end{array}$ & $\begin{array}{c}\text { Level of } \\
\text { Significance }\end{array}$ & $\begin{array}{c}\text { Mean } \\
\text { Difference }\end{array}$ \\
\hline $\begin{array}{c}\text { The Feeling of } \\
\text { Self-Efficacy }\end{array}$ & -9.109 & 58 & 0.0001 & -14.400 \\
\hline
\end{tabular}

The results of the multiple regression analysis in predicting the feeling of self-efficacy by personality characteristics among aged people have been reported in Table 3. The predictor model was eventually obtained using two variables of neuroticism and conscientiousness after removing meaningless predictor variables; other predictor variables were also removed due to the lack of meaning in their coefficients.

According to the above mentioned table, the simultaneous relation between personality characteristics and the feeling of self-efficacy and correlation coefficient was significant with 0.708 with the confidence level of $99 \%$. Squared correlation coefficient of 0.502 shows that $50.2 \%$ of self-efficacy scattering is because of personality characteristics' scattering. Furthermore, mutual accreditation of the correlation coefficient is adjusted with the squared correlation coefficient which ends in the difference of 0.006. (0.502-0.496- 0.006) shows that if the equation is generalized to the whole population, the maximum reduction of the coefficient of determination will be $0.6 \%$; therefore, the equation will be valid and can be generalized to the society. The significance of $\mathrm{F}(\mathrm{sig}<0.001)$ shows that if other predictor variables are added to the equation, the correlation coefficient will be significant. Besides, the result of Durbin-Watson test which is equal to 2.0782.078 confirms the lack of self-correlation (errors' independence) in predictor variables.

Table 3. The Summary of the Predictive Model for Self-Efficacy Feeling by Personality Characteristics

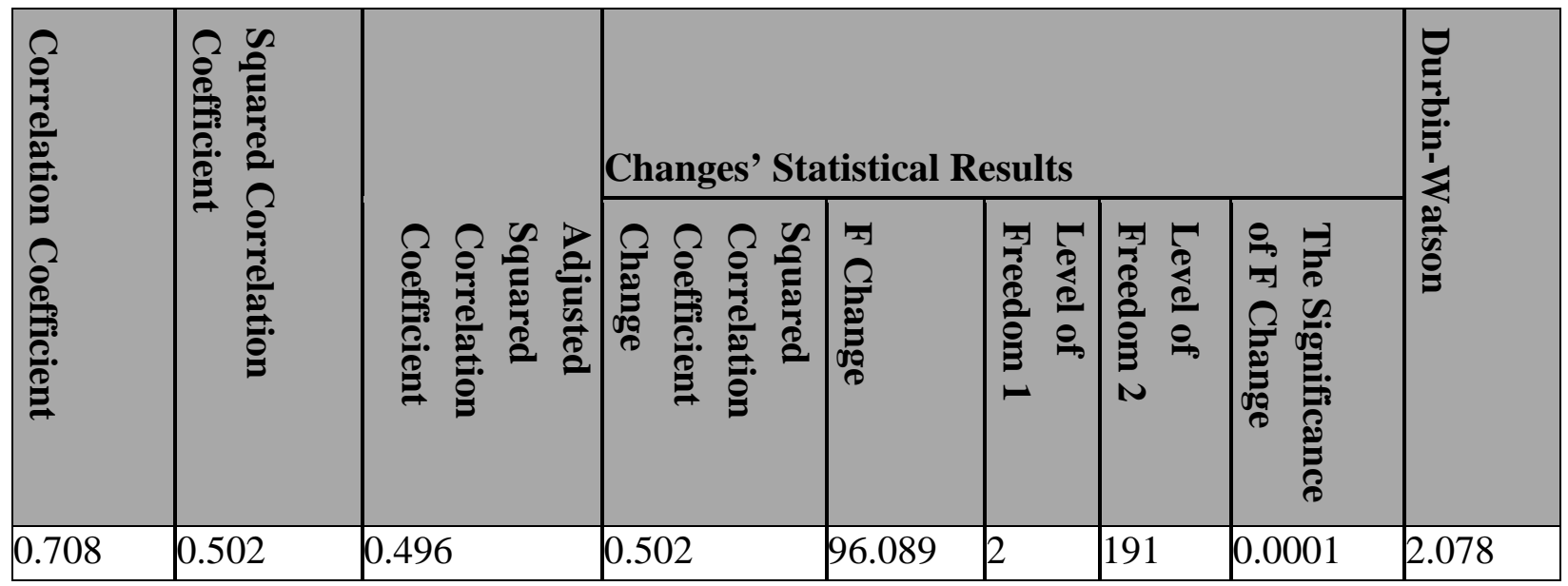

(C) The International Journal of Indian Psychology, ISSN 2348-5396 (e)| ISSN: 2349-3429 (p) | 108 
According to the obtained results in Table 4, the null hypothesis is rejected (sig< 0.001$)$ and the equation predicting the feeling of self-efficacy by personality characteristics among successful and unsuccessful aged people is significant with confidence level of $99 \%$.

Table 4: Variance Analysis Test for the Significance of the Regression Equation

\begin{tabular}{|c|c|c|c|c|c|}
\hline Equation & $\begin{array}{c}\text { The Sum of } \\
\text { Squares }\end{array}$ & $\begin{array}{c}\text { Level of } \\
\text { Freedom }\end{array}$ & Squared Mean & F & $\begin{array}{c}\text { Level of } \\
\text { Significance }\end{array}$ \\
\hline Regression & 9407.720 & 2 & 4703.860 & 96.089 & 0.0001 \\
\hline Residual & 9350.032 & 191 & 48.953 & & \\
\hline Total & 18757.753 & 193 & & & \\
\hline
\end{tabular}

The equation predicting self-efficacy feeling by personal characteristics is as follows:

SE $=30.907-0.484 \mathrm{~N}+0.646 \mathrm{C}$

SE: Self-Efficacy

$\mathrm{N}$ : Neuroticism

C: Conscientiousness

\section{DISCUSSION AND RESULTS}

The findings showed that there is a significant relation regarding personality characteristics between successful and unsuccessful aged people. Besides, according to Table 1, there is a significant difference in terms of characteristics such as extraversion, consciousness, and being delighted between successful and unsuccessful aged people. These results were in line with the results obtained by Geriatr (2009) and Jackson et al. (2009).

Based on the obtained results in Table 2, there is a significant difference regarding the feeling of self-efficacy between successful and unsuccessful aged people. Self-efficacy beliefs can correctly predict behaviors and not real abilities of behavior, since these beliefs are instruments which determine what activities can be performed by what people. The role of these beliefs' mediators is to realize why people with same skills and knowledge have different performances. The results of this section are in line with Aben et al. (2011), Davy (2011), Costa et al. (2010), Navarro et al. (2008), and Halahan and Halahan. When the elderly consider the world around them as predictable and feel that they can appropriately face challenges in life, they reach to calmness and personal satisfaction. Fry and Kiz (2010) consider self-efficacy as the predictor of subjective well-being and a framework for life satisfaction. Self-efficacy beliefs are positively related with physical health and the feeling of well-being. The feeling of lack of control on negative events and being dependent on others are of the main reasons of depression and psychological problems among the elderly.

(c) The International Journal of Indian Psychology, ISSN 2348-5396 (e)| ISSN: 2349-3429 (p) | 109 


\section{The Relation between Personality Characteristics and Self-Efficacy and Successful and Unsuccessful Aging}

The results of the correlation coefficient of the third hypothesis have been presented in Table 3. Based on the information of this table, the hypothesis of characteristics of neuroticism, extraversion, conscientiousness, and being acceptable is supported and the null hypothesis is rejected with 99\% certainty.

Self-efficacy has raised major discussions among the experts in the field in all ages, especially among the aged people in terms of age conditions, physiologic changes, and their vulnerability. Bandura defines his theory as the best predictor of behaviors and behavior changes; it also pictures an image of human beings' behavior whose most important element is self-efficacy. Self-efficacy affects people's ability and resistance against anxiety, vulnerability, tension, depression, and other psychological disorders; the need to compatibility with physical, psychological, and social changes is of the necessities of aging and high general efficacy among the aged people will help them become compatible with the specific conditions of this age. The feeling of disability and non-efficacy in becoming compatible with these changes results in madness and anxiety among aged people. The social-cognitive theory increasingly emphasizes on the role of cognitive processes due to improper self-measurements and especially, regarding the feeling of weak self efficacy beliefs in psychopathology.

Totally, it can be concluded that weak self-efficacy beliefs is one of the main problems among aged people which result in unsuccessful aging. Analyzing the relation between these components (self-efficacy characteristics) can results in the identification of variables related with successful aging; the results of the present research can provide the situation for conducting instructional and consultancy attempts related with successful aging.

\section{REFERENCES}

Aben, L; Ponds, RW. HM; Visser ,M. M; Busschbach, J. V; Ribbers, G. M. (2011). Memory complaints in chronic stroke patients are predicted by memory self-efficacy rather than memory capacity. . Journal Archive Collection 31 (6.)

Bandura, A; Locke, E. A. (2003). Negative self-efficacy and goal revisited. Journal of Applied Psychology. 88 (1): 87-99.

Bond, J., \& Cornor, L. (2010). Life Quality and Aged People. (K. Seyed Mohaqeqi, Trans.) Tehran: Danje.

Costa, L, M; Mahera, C. G; Mcaauleya, J. H; Hancockb, M. R; Smeetsc, RJ. EM. (2010). Selfefficacy is More important than fear of movement in mediating the relationship between pain And disability in chronic low back pain. European Journal of Pain 15 (2): 213-219.

Davy, J. (2011). Self-efficacy and weight loss. Retrieved July 13, 2011, from http/www.aginginaction.com/2011/05/ Self-efficacy-and-healthy-weight-loss.

Depp, C. A; Jeste, D. V. (2006). Definition and of successful aging: a comprehensive review of larger Quantitative studies. . American Journal of Geriatric Psychiatry 14 (1): 6-20

(c) The International Journal of Indian Psychology, ISSN 2348-5396 (e)| ISSN: 2349-3429 (p) | 110 


\section{The Relation between Personality Characteristics and Self-Efficacy and Successful and Unsuccessful Aging}

Ebstrup, J. F; Eplov, L. F; C; Jorgensen, T. (2011). Association between the five factor personality Traits and perceived stress is the effect mediated by general self-efficacy? Anxiety Stress Coping 24(4).

Foos, P. W; Clark, M. C. (2009). Human aging. Boston,MA: Peas on/Ahyn and Baco

Fry, P. S; Keyes, CL. M. (2010). New Frontiers in Resilient aging. New York: Cambridge university press.

Gliken, M. D. (2009). Evidence-based consulting and psychotherapy for an aging population. Macmillan: solution.

Geriatr soc, J. AM. (2009). Personality traits of centenarian's off Spring. Current Gerontology Geriatrics Research

57(4): 683-68.

Halahan, C. K; Halahan, C. D. (2006). Life stress, hassles and self-efficacy in aging: a replication and Extension. Areplication and Extension.17(6 ): 574-592 .

Hofer, S. M; Alwin, D. F. (2008). Cognitive aging inter disciplinary perspective. India: pvt.L,td

Hoyer, J. W; Roodin, P. A . (2009). Adult development and Aging. Boston: MacMillan Inc.

Jakson, J; Balota, D. A; Head, D. (2009). Exploring the relationship between personality and regional brain volume healthy aging. Neurobiology of Aging 32 (12): 2162-2172.

Navarro, A. B; Bueno, B; Buz, J; Mayoral, P. (2008). Perception of self-efficacy in coping with problems and its contribution to life satisfaction in very old very old .Revista Española de Geriatría y Gerontología 41(4): 222-227.

Orrell, M; Spector, A. (2009). Psychology of aging. Farenham: Ashgate.

Pervin, L. A; Cervone, D; John, O. P. (2005). Personality theory and research. The United States .John wily \& sons, Inc.

Strobel, M; Turnasjan, A; Sporrle, M. (2011). Be yourself, believe in yourself, and be happy: self-efficacy as a mediator between personality factors and subjective well-being. Scandinavian Journal of Psychology 52(1)

Schenhofen, S. E; Reynilds, C. A; Pederse , N. L, Gatz, M. (2010). Cognitive engagement and cognitive aging. is openness protective? Psychology and Aging, 25 (1): 60-73

Veljko, J. (2011). Personality and subjective well-being: one neglect model of personality and forgotten aspect of subjective well-being. Personality and Individual Differences, 5(5): 631-935.

Vaillant, G. E; Mukamal, K. (2001). Successful aging. .American Journal of Psychiatry. 158 (6): 839-874.

How to cite this article: M Kivi, A Motamedy (2016), The Relation between Personality Characteristics and Self-Efficacy and Successful and Unsuccessful Aging, International Journal of Indian Psychology, Volume 3, Issue 3, No. 11, DIP: 18.01.200/20160303, ISBN: 978-1-36521307-6

(C) The International Journal of Indian Psychology, ISSN 2348-5396 (e) | ISSN: 2349-3429 (p) | 111 